Paper ID 108

\title{
AGGREGATE POLISH VALUE AND ITS CONSIDERATION IN SKID PREDICTION MODELS DEVELOPED IN ARGENTINA
}

\author{
Marta, PAGOLA \\ National University of Rosario \\ Argentina \\ pagola@fceia.unr.edu.ar
}

\author{
Oscar, GIOVANON \\ National University of Rosario \\ Argentina \\ ogiovanon@gmail.com
}

\begin{abstract}
In 1999, asphalt mixes with special characteristics have begun to be used in Argentina, especially open graded mixes with polymer modified asphalt and low thickness, SMA and F10 of Spanish Specifications, using granitic aggregates. Because in Argentina there were no experiences about these mix types from the point of view of skid resistance, since the beginning of construction a surveillance program have begun.

Aggregates were tested using Accelerated Polishing, Micro Deval and Los Angeles tests. There were found that Polish Stone Value results (PSV) of Argentine granitic aggregates are low, with values around 40 , because of that, surveillance program was followed with more attention.

A test section evolution of $4.4 \mathrm{Km}$ and 5 lanes with F10 surface mix on one of highest traffic of Argentina was followed. Tests were done on left track of each lane, two lanes of light traffic, and two lanes of heavy traffic. Test section was analyzed in sectors of $1 \mathrm{Km}$. Friction coefficient was measure using British Pendulum Tester, and macrotexture was measured using Sand Patch method. As a result was developed a skid prediction model that considers PSV, traffic volume and the age in service, as parameters.

Additionally, on PSV test, friction was measured before and after polishing. Results indicated that PSV obtained before test is similar to the initial value of skid model, which is valid after the initial period of two month under traffic.
\end{abstract}

Keywords: aggregates, skid resistance, prediction models.

\section{INTRODUCTION}

In Argentina, road surface asphalt layers were traditionally designed to satisfy structural criteria, without consideration of users and their security. At the end of 90's was implemented a Road Concession system in more than $9000 \mathrm{Km}$ of road. Since then, private companies do road maintenance and improvements, and National Road Administration controls surface quality. To satisfy user's requirements, new types of surface asphalt layers were used. The users and their security have begun to be considered, especially in highways and roads with high level of traffic.

Related with equipments, the National Road Administration has two Mu meter equipments since years 80's and one Scrim-tex acquired in 1999. At Provincial Road Administrations level, there are no equipments. And private companies have various British Pendulum Testers and two Griptesters.

Since 1999, a test section evolution of $4.4 \mathrm{Km}$ and 5 lanes with F10 surface mix on one of highest traffic of Argentina was followed. Friction coefficient was measure using British Pendulum Tester (BPN), and 
macrotexture was measured using Volumetric Method (MTD). As a result, macrotexture and skid prediction models were developed, considering PSV, traffic volume and age in service.

The objective of study was to analyze the variation of road surface adherence under traffic. Performance models to predict the evolution of individual parameters (skid and macrotexture), and IFI were developed, based in local experience, considering materials, asphalt mix surface layers, traffic and climate.

On the other hand, our University has the only PSV test equipment to analyze aggregates; working together with National Road Administration were tested a lot of aggregates from commercial quarries. (Pagola M. and Giovanon O., 2010)

Then, the relationship between friction and PSV was analyzed, and results are presented in the present paper.

\section{MEASUREMENTS}

The program to follow skid resistance and macrotexture evolution was implemented in a highway section in 1999, on a recently built road surface. The section has 4400 meters of length with 5 lanes, and it is located in one of highways with higher traffic level of Argentina. F10 asphalt mix was used. This was the first experience using this mix, which was designed looking for high macrotexture. This section does not have the best quality construction obtained at that opportunity, but can be considered as representative.

Measurements of skid resistance and macrotexture were done during night, because of traffic. Always were used the same equipments and methodology. Stationary equipments: British Pendulum Tester and Volumetric Method were used. Results were taken on left track of each lane, on internal lanes 1 and 2 of light traffic, and external 4 and 5 lanes of heavy traffic. On central lane no measurements were made because there was no security to do that. (Esteban D. et al, 2011)

To organize measurements, section was divided in 4 sub sections of 1000 meters on each lane. In each sub section 35 results per year were obtained, and the average of them was used to analyze the evolution.

Results reported here were obtained from December 1999 to July 2010. Macrotexture was measured with more frequency during first year, and skid resistance measurements have begun after a period of 7 month under traffic.
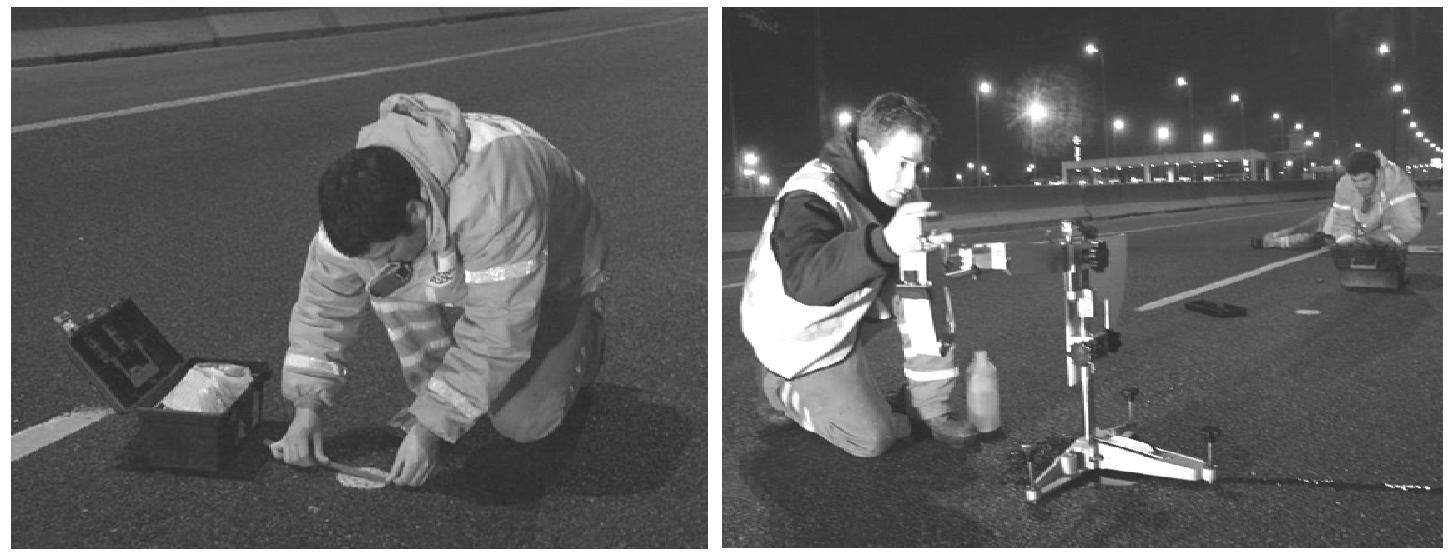

Figure 1: Macrotexture and skid resistance measurements 


\section{ROAD SURFACE, ASPHALT MIX CHARACTERISTICS}

Asphalt mix was designed following gradation of asphalt mix type F10 of Spanish normative. And asphalt cement was modified with $4 \%$ of SBS polymer. Aggregates used in asphalt mix were crushed granite from Olavarría, located in the center of Buenos Aires Province. Coarse aggregates characteristics are shown in Table 1. This material is very used in structural asphalt layers because it has good results in The Angeles abrasion test and quarry location is near places with high demand of use. This is the first time that aggregates are analyzed from road surface adherence point of view.

Table 1: Coarse Aggregate Test Results

\begin{tabular}{l|l|c}
\hline \multirow{3}{*}{$\begin{array}{l}\text { Coarse aggregate size } \\
06-12 \mathrm{~mm}\end{array}$} & \multicolumn{1}{|c|}{ Test } & Result \\
\cline { 2 - 3 } & The Angeles & $23 \%$ \\
\cline { 2 - 3 } & Polish Stone value & $38-41$ \\
\cline { 2 - 3 } & Flat particles & $12-20 \%$ \\
\hline
\end{tabular}

During PSV test were taken two results, PSVini of aggregate without polish and PSV after polishing. Granite coarse stone used here has PSVini $=60$ (aggregate without polishing), and final PSV $=40$. On the road, this reduction is done along time in service under traffic, and this time can be different in relationship with presence of dirt on surface, which acts as an abrasive.

When surface is new, aggregates collaborate with PSVini value or similar, depending of polishing during asphalt mix elaboration. PSV result of this aggregate is low, but asphalt mix was designed with high macrotexture to collaborate in obtaining good skid resistance results.

\section{CLIMATE}

Section is located in a place with mild climate, with warm summers and fairly cool winters. Average annual temperature is $17^{\circ} \mathrm{C}$. The coldest month is July, with an average temperature of $10^{\circ} \mathrm{C}$. There are rare frost and no snow. The hottest month is January with an average temperature of $25^{\circ} \mathrm{C}$. On the other hand, average annual rainfall is $1100 \mathrm{~mm}$.

\section{TRAFFIC}

Annual average daily traffic (AADT), total in both directions, has growing tendency since 1999, with two marked periods with no growing in correspondence with economic crisis occurred in Argentina during years 2001 and 2008. This evolution is shown in Figure 2. Traffic composition and lane distribution are shown in Table 2.

Table 2: Traffic Composition And Lane Distribution

\begin{tabular}{l|c|c|c|c|c|c}
\hline Vehicle type & Lane 1 & Lane 2 & Lane 3 & Lane 4 & Lane 5 & Total \\
\hline Cars & $25.9 \%$ & $28.2 \%$ & $17.0 \%$ & $9.6 \%$ & $5.1 \%$ & $85.8 \%$ \\
\hline Light trucks & $0.1 \%$ & $0.2 \%$ & $2.3 \%$ & $2.4 \%$ & $1.9 \%$ & $6.9 \%$ \\
\hline Heavy trucks & $0.0 \%$ & $0.2 \%$ & $1.5 \%$ & $3.5 \%$ & $2.2 \%$ & $7.4 \%$ \\
\hline Total & $26.0 \%$ & $28.6 \%$ & $20.8 \%$ & $15.5 \%$ & $9.2 \%$ & $100 \%$ \\
\hline
\end{tabular}




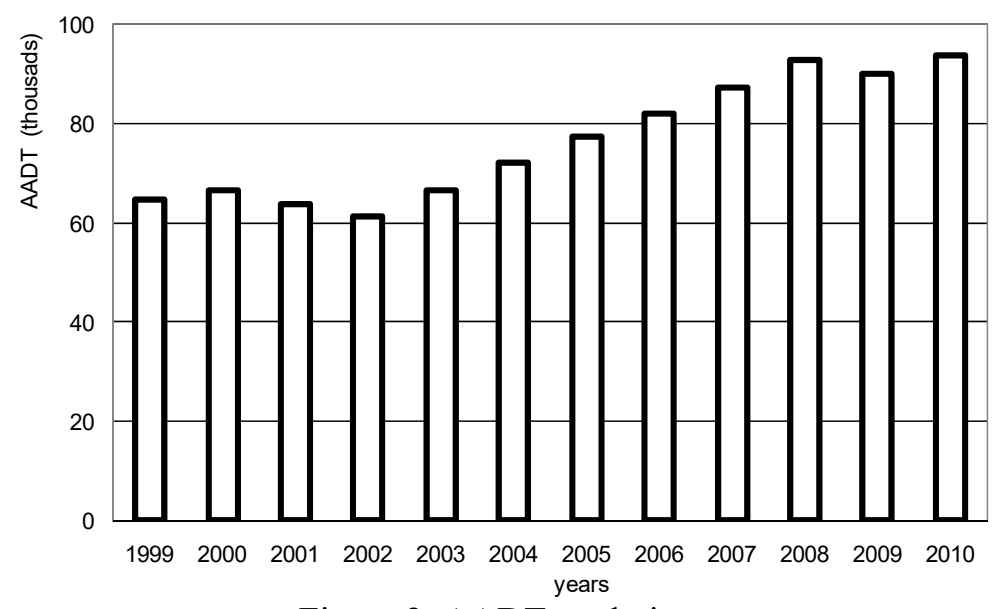

Figure 2: AADT evolution

\section{SURFACE CONDITION EVOLUTION}

During observation period were made only punctual activities of maintenance in the section under study, because of some fine cracks and rutting on lanes 4 and 5. The intervention area during this period was less than $5 \%$ with respect to analysis area.

At date January of 2011 the section presents the quality level shown in Table 3, expressed in PSI. PSI is the Present Serviceability Index, with values from 5 to 0 , where 5 represents the best quality and 0 the worse.

Table 3: Surface Condition, Year 2011

\begin{tabular}{l|c|c|c|c}
\hline \multirow{2}{*}{} & \multicolumn{2}{|c|}{ Internal lanes } & \multicolumn{2}{c}{ External lanes } \\
\cline { 2 - 5 } & Lane 1 & Lane 2 & Lane 4 & Lane 5 \\
\hline PSI & 3.2 & 3.2 & 3.2 & 3.1 \\
\hline
\end{tabular}

\section{ROAD SURFACE ADHERENCE MODELS}

Using BPN and MTD results, obtained during 11 years, deterioration models were developed. It is important to remark, that they are valid for the same conditions where the experience was developed: clean road surface (shoulders are paved and there are not unpaved accesses) and mild climate (warm summers and cool winters). (Pagola M. and Giovanon O., 2012) (Sinhal et al, 2011) (Lorino T., 2008).

\section{Macrotexture model}

The model developed for macrotexture evolution is:

$$
M T D=\text { MTDini }-3.1 * 10^{-6} * \text { age } * \log _{10}(\text { CVDini })-0.00265 *(\text { age } * \text { CVDini } * r)^{0.432}
$$

Where:

MTD

MTDini

CVDini

age

r macrotexture at certain age in service $(\mathrm{mm})$

macrotexture initial value $(\mathrm{mm})$

number of commercial vehicles per day

age in service (days)

traffic annual growth rate 
In Figure 3 model prediction and measurements are shown. Model prediction is represented with line and measurements with points. The model and coefficients used for both lanes are the same, and it follows each lane evolution using particular data of each one.

Model coefficients were obtained looking for minimize the estimation error, using square minimum. Estimation error is $0.07 \mathrm{~mm}$, using data of lanes 1 and 5 .

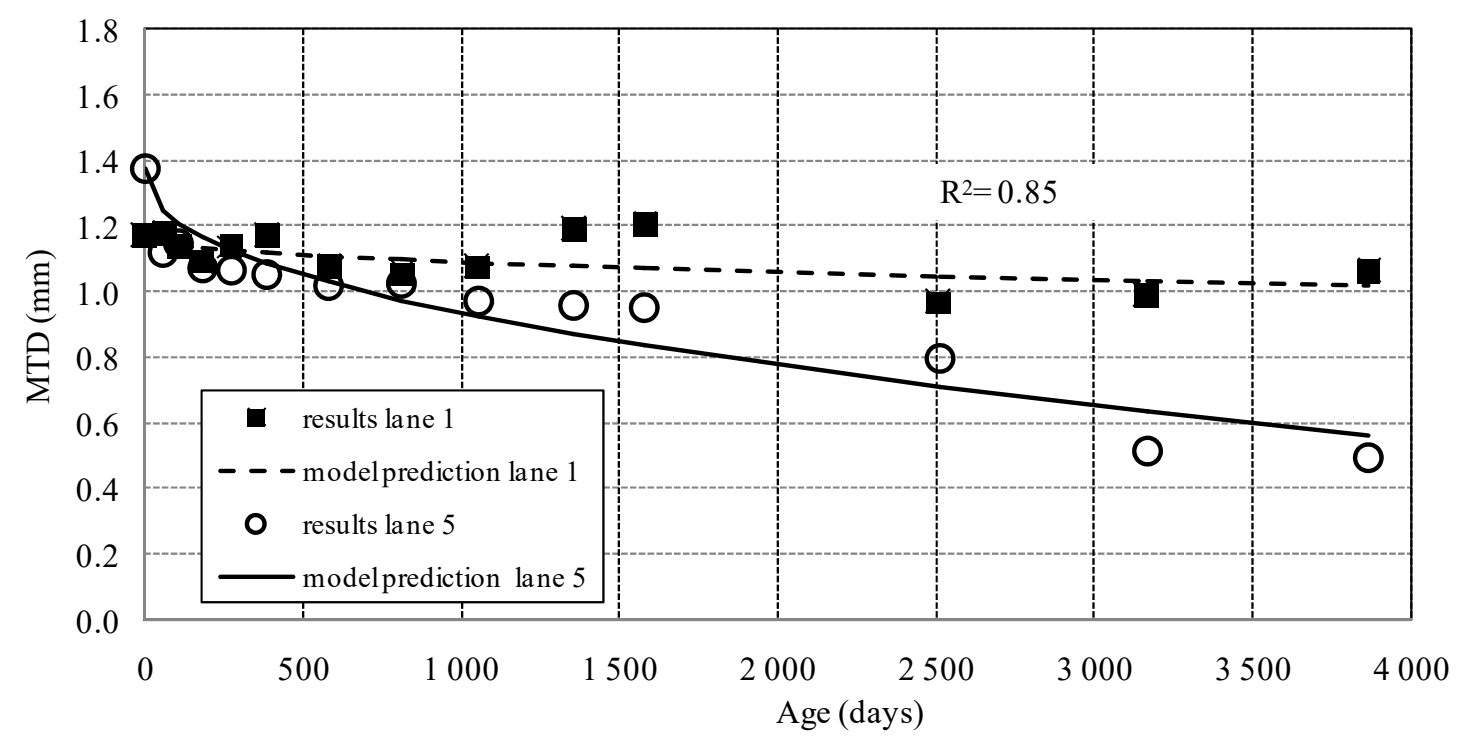

Figure 3: Macrotexture model prediction and measurements

\section{Skid resistance model}

The model developed for skid resistance evolution is:

$$
B P N=P S V * 1.53-0.00470 *\left(\text { AADTini } *(1 * r)\left(\frac{\text { age }}{365}\right)\right)^{0.46} * \text { age } e^{0.407}
$$

Where:

$\begin{array}{ll}\text { BPN } & \text { BPN at certain age in service } \\ \text { PSV } & \text { Polish Stone value of aggregates } \\ \text { AADTini } & \text { Initial AADT } \\ \text { age } & \text { age in service (days) } \\ \mathrm{r} & \text { traffic annual growth rate }\end{array}$

In Figure 4, measurement results and model prediction are shown. Model prediction is represented with line and measurements with points. Model coefficients used are the same for all lanes, and the model follows each lane evolution using particular data of each one.

In a similar way than in macrotexture model, coefficients were obtained looking for minimize estimation error, using square minimum. Estimation error is 1.4 BPN, using data of lanes 1 and 5.

Initial value of new surface skid resistance, measured with British Pendulum, depends on PSV of aggregates because the other terms of equation are null. In the model, the coefficient of PSV represents 
that surface begins the life with aggregates in "new" condition, only polished during mix elaboration, and it is 1.53 times PSV test result.

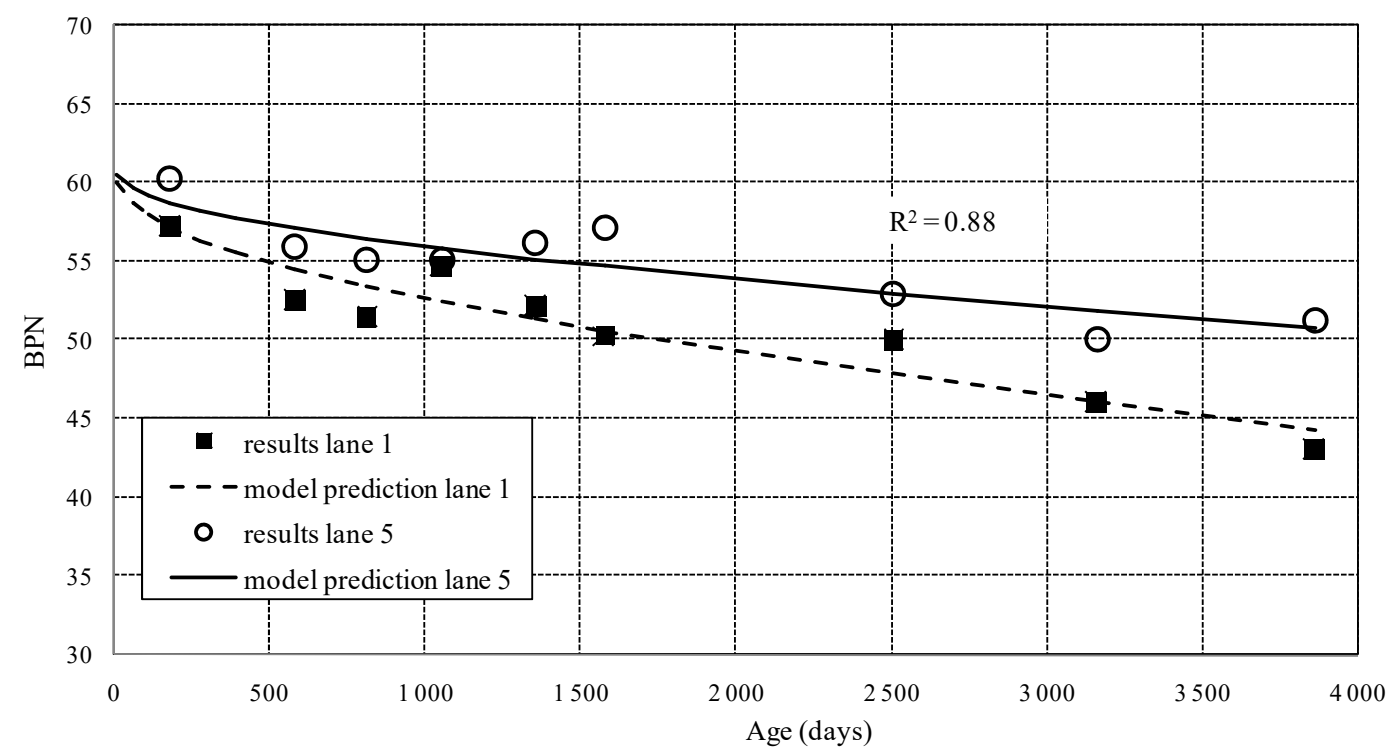

Figure 4: Skid resistance model prediction and measurements

\section{ANALYSIS OF PSV RESULTS AND SKID RESISTANCE RELATIONSHIP}

During PSV test were taken two results, PSVini of aggregate without polish and PSV after polishing. Granite coarse stone used here has PSVini $=60$ (aggregate without polishing), and PSV $=40$. The relation between results is:

$$
\frac{\text { PSV }}{\text { PSVini }}=1.5
$$

Where:
PSV
final test result
PSVini result before polishing

In the model obtained for skid resistance, the initial value of skid resistance depends only from PSV result of aggregate, and the coefficient is 1.53. Then the relation between skid and PSV is direct, and the PSV test result is an indicator of surface skid initial level. (Szatkowski W. and Hosking J., 1972).

\section{CONCLUSIONS}

Macrotexture and skid resistance were followed during 11 years under traffic on a section located on an important highway in Argentina. It was the first experience in Argentina, using surface asphalt mix type F10 of Spanish Specifications, built with granitic coarse aggregate and polymer modified asphalt. Authors appreciate the data provision to the Road Concession Company.

Using BPN and MTD results, obtained during 11 years, deterioration models were developed. In skid resistance model obtained, the initial value of skid resistance depends only from PSV result of aggregate, and the coefficient is 1.53 . This factor is very similar than the relation between initial and final PSV results, in PSV test. 
Then the relation between skid and PSV is direct. The PSV test final result is an indicator of adherence level that can be achieve in service, using British Pendulum.

\section{REFERENCES}

Esteban D., Páramo J., Pagola M. et al., 2011. Road surface performance after 11 years in service. $15^{\circ}$ CILA, Brasil.

Lorino T., 2008. Pavement surface characteristics evolution. SURF 2008, Slovenia.

Pagola M. and Giovanon O., 2010. Agregados pétreos y adherencia neumático calzada. $4^{\text {to }}$ Congreso de infraestructura de transportes, Brasil.

Pagola M. and Giovanon O., 2012. Adherence Prediction Models Developed in Argentine, $7^{\text {th }}$ Symposium on Pavement Surface Characteristics SURF 2012, USA.

SinHal R., Dondavand J. and Kennedy C., 2011. Long term study of skid resistance on in-service roads in England. 3er International surface friction conference. Australia.

Szatkowski, W., and Hosking, J., 1972. The effect of traffic and aggregate on the skidding resistance of bituminous surfaces. TRRL Laboratory Report LR 504. 